\title{
PRÁTICAS DOCENTES NO AMBIENTE PRISIONAL: entre a cela e a sala de aula
}

\author{
Kely Rejane Soura dos Anjos de Carvalho \\ Jocyleia Santana dos Santos \\ Daniela Patrícia Ado Maldonado
}

\section{Resumo}

No desígnio de conhecer a percepção de professoras e alunas quanto à realidade educacional em que estão inseridas, na Unidade Prisional Feminina (UPF) de Pedro Afonso, no Tocantins (TO), o objetivo propulsor dessa pesquisa foi compreender como as docentes exercem sua prática pedagógica e como ocorre o processo de ensino e aprendizagem na referida instituição, locus desse estudo. $\mathrm{O}$ corpus da investigação científica foi composto pelas narrativas de quatro professoras atuantes exclusivamente na UPF de Pedro Afonso e de três alunas que aceitaram, voluntariamente, participar do processo investigativo. A metodologia utilizada amparou-se na história oral, que viabiliza o surgimento de vozes à margem dos direitos e da sociedade e realizada por meio das narrativas colhidas nas entrevistas individuais. Para consecução do roteiro semiestruturado de perguntas, vários fatores foram considerados, tais como: a forma de admissão das professoras, as técnicas e/ou práticas pedagógicas desenvolvidas e as possíveis contribuições oriundas da educação para a ressocialização das reeducandas. Por intermédio da sistematização, análise e entrelaçamento dos dados descortinaram-se os resultados que evidenciaram um distanciamento entre a legislação e o cotidiano do sistema penitenciário, bem como a falta de materiais didáticos apropriados, salas multisseriadas e a inexistência de capacitação específica às professoras entrevistadas. Fatores determinantes que se configuram como verdadeiros desafios à prática docente no cárcere.

Palavras-chave: educação em prisões; práticas pedagógicas; docência na prisão.

\section{TEACHING PRACTICES IN THE PRISON ENVIRONMENT:} between the cell and the classroom

\begin{abstract}
With the purpose of knowing the perception of teachers and students regarding the educational reality in which they are inserted, in Pedro Afonso Female Prison Unit (UPF), Tocantins (TO), the main objective of this research was to understand how teachers exercise their pedagogical practice and how the process takes place. teaching and learning at the institution, the locus of this study. The corpus of scientific investigation was composed of the narratives of four teachers working exclusively at Pedro Afonso Female Prison Unit and three students who voluntarily accepted to participate in the investigative process. The methodology used was supported by oral history, which enables the rise of voices neglected both by society and their rights and carried out through the narratives collected in individual interviews. In order to achieve the semi-structured questionnaire, several factors were considered, such as: the form of admission of teachers, the techniques and / or pedagogical practices developed and the possible contributions from education for the re-insertion of reeducated women. Through the systematization, analysis and interlacing of the data, the results showed a gap between the legislation and the daily life of the penitentiary system, as well as the lack of appropriate didactic materials, multi-grade rooms and the lack of specific training for the interviewed teachers. Determining factors that constitute real challenges to teaching practice in prison.
\end{abstract}

Keywords: education in prisons; pedagogical practices; teaching in prison. 


\section{PRÁCTICAS DOCENTES EN EL AMBIENTE CARCELARIO:} entre la celda y la sala de aula

Resumen

Con el deseo de conocer la percepción de profesoras y alumnas sobre la realidad educativa donde están insertas, en la Unidad Carcelaria de Mujeres de Pedro Afonso (UPF), Tocantins (TO), el objetivo principal de esta investigación fue comprender cómo los docentes ejercen su práctica pedagógica y cómo ocurre el proceso de enseñanza y aprendizaje en esa institución, locus de este estudio. El corpus de la investigación científica estaba compuesto por las narraciones de cuatro profesoras, que trabajan exclusivamente en la UPF de Pedro Afonso y tres estudiantes, que aceptaron voluntariamente, participar en el proceso de investigación. La metodología utilizada se apoyó en la historia oral, que hace posible la aparición de voces que están al margen de los derechos y de la sociedad y llevada a cabo a través de relatos recogidos en las entrevistas individuales. Para lograr el cuestionario semiestructurado, se consideraron varios factores, tales como: la forma de admisión de docentes, las técnicas y/o prácticas pedagógicas desarrolladas y las posibles contribuciones oriundas de la educación, para la resocialización de las internas reeducadas. A través de la sistematización, el análisis y el entrelazado de los datos, se revelaron los resultados que evidenciaran una brecha entre la legislación y la vida cotidiana del sistema penitenciario, así como la falta de materiales didácticos apropiados, salas de varios grados integrados y la inexistencia de capacitación específica para los profesores entrevistados. Factores determinantes que se constituyen como desafíos reales para la práctica docente en prisión.

Palabras clave: educación en prisiones; prácticas pedagógicas; docencia en la prisión.

\section{PALAVRAS INICIAIS}

"A privação da liberdade é a privação do tempo. Tempo em movimento, tempo extramuros, tempo social. A vida no cárcere é composta pela espera, pelo passar dos dias para que outros dias possam ser vividos" (ANGOTTI, 2011, p. 301). Tempo que, ao ser usado para a prática de ensino e aprendizagem, no interior da UPF de Pedro Afonso, no estado do Tocantins, tornou-se objeto de estudo dessa pesquisa que buscou conhecer a concepção de tempo escolar, seja pelas que habitam a prisão, seja pelas que a vivenciam como ambiente de trabalho e sustento, no exercício da docência.

Ressocializar, palavra da moda, presente em muitos discursos, e que muito aparecerá nesse texto, requer que a conheçamos mais profundamente. Para isso, buscou-se aporte em Julião (2009, p. 67), que esclarece que "[...] nos principais dicionários de Língua Portuguesa, ressocialização é definido como ato ou efeito de ressocializar. Já ressocializar é tornar a socializar". Nesse sentido, enquanto o termo "reeducanda" é usado para designar as internas que se encontram detidas na UPF de Pedro Afonso, as que estudam na escola que lá existe são denominadas apenas "alunas".

Os resultados que aqui se apresentam são oriundos de uma investigação científica mais ampla, em nível de mestrado, e que consistiu em compreender como a oferta de educação na UPF de Pedro Afonso busca contribuir para a ressocialização das reeducandas, sob o olhar de alunas e professoras. No transcurso de rememoração das participantes da pesquisa, por meio da oralidade, a fala e as reminiscências foram ferramentas de valor imensurável.

Muito se fala na necessidade de ressocializar o preso, seja pelo trabalho, seja pelo estudo. Mas na prática, ainda, são poucas as instituições penitenciárias brasileiras que oferecem programas socioeducativos que busquem a ressocialização das pessoas em situação de prisão. No intuito de implantar e ampliar mecanismos que promovam a ressocialização no sistema prisional 
brasileiro, há a Lei de Execução Penal Brasileira (LEP), promulgada em 1984 que, ao ser alterada pela Lei n. 12.245 de 2010, passou a determinar que a população carcerária deve exercer algum tipo de atividade laboral, bem como dispõe sobre a obrigatoriedade de oferta do ensino fundamental e a implantação de biblioteca nas instituições penais. O que se constata, na realidade, é que em 2015 apenas uma em cada dez pessoas reclusas realizava algum tipo de atividade educacional no país, conforme dados informados pelo Ministério da Justiça, por meio do Levantamento Nacional de Informações Penitenciárias (INFOPEN).

À frente do processo de ressocialização socioeducacional, presente em parte dos presídios do país, encontra-se a educação de jovens e adultos (EJA) que, por constituir uma forma de educação diferenciada, é a modalidade utilizada no sistema prisional brasileiro. Consta que, por sua vez, quando associada à educação em prisões, impõe ao docente o desafio de conciliar suas respectivas peculiaridades. Assim sendo, é necessário considerar que os professores inseridos nessa modalidade de ensino devem adotar uma didática específica que, além de priorizar o ensino e a aprendizagem, de forma diferenciada, também sejam capazes de auxiliar no processo de reinserção do preso na sociedade e no mercado de trabalho. O que desperta a necessidade de compreender se a formação didático-pedagógica recebida por esses profissionais dispõe de aporte teórico-metodológico que os capacite para lidar com pessoas que têm o seu maior bem retirado, sua liberdade.

Sob essa ótica, no intuito de atingir os objetivos almejados, realizamos um estudo norteado pela história oral, método regido pela preocupação em conhecer as significações das ações e relações entre pessoas ou grupos. Nessa perspectiva, o tipo utilizado foi a história oral temática, que é realizada com grupos de indivíduos que possuem algum acontecimento em comum. Assim sendo, o corpus da pesquisa foi composto por alunas e professoras que atuam juntas na educação prisional da UPF de Pedro Afonso, no Tocantins.

As alunas que participaram dessa pesquisa cumprem pena em regime fechado e buscam, por meio da educação, se reinventarem. As demais participantes são professoras que se dedicam ao máximo para que elas e a ressocialização se encontrem. E no intuito de preservá-las, conforme orientado pelo Comitê de Ética e Pesquisa em seres humanos, da Universidade Federal do Tocantins (UFT), por meio do parecer consubstanciado n. 3.096 .185 de 2019, utilizamos apenas o último nome das entrevistadas e o ano em que a entrevista foi concedida.

\section{APORTE TEÓRICO}

A reclusão de pessoas em ambientes fechados mostrou-se ineficaz no processo de reabilitação do preso e começou-se então a pensar em meios para devolver o indivíduo ressocializado ao convívio da sociedade (FOUCAULT, 1987). Nesse sentido, é que há toda uma gama regulamentar que dispõe sobre a recuperação da pessoa em situação de prisão, por meio da educação e do trabalho. Sob tal perspectiva, vamos ao encontro do Artigo 17 da Lei n. 7.210, de 1984, que estabelece que a "[...] assistência educacional compreenderá a instrução escolar e a formação profissional do preso e do internado”. O Artigo 208 da Constituição Federal de 1988, por seu turno, preconiza que é dever do Estado proporcionar educação para todos, inclusive para os que não tiveram acesso à educação formal na idade adequada. Nessa acepção, podemos fazer uma ponte com o pensamento de Foucault (1987, p. 224), que enfatiza: "A educação do detento é, por parte do poder público, ao mesmo tempo uma precaução indispensável no interesse da sociedade e uma obrigação para com o detento". 
Sobre o perfil da população que ocupa as cadeias brasileiras, Almeida (2016, p. 42) enfatiza que "[...] são em grande parte jovens, pardas, pobres e com baixa escolaridade", informação corroborada pelos dados do INFOPEN (2016), cuja pesquisa mais recente revelou que o perfil do interno penitenciário brasileiro é constituído da seguinte forma: $55 \%$ são jovens na faixa etária de 18 a 29 anos de idade; economicamente produtiva; 64\% são negros e pardos; $61 \%$ não concluiu o ensino fundamental e são, em maioria, oriundos de grupos menos favorecidos da população (INFOPEN, 2016). Números que estão na contramão do que preconiza a legislação brasileira sobre a oferta efetiva de ensino em todo o sistema penitenciário e que atestam "A vulnerabilidade a que está exposta a camada mais pobre da pirâmide social e intensifica a desigualdade que se acha representada fidedignamente nas cadeias do país (CARVALHO, 2019).

Como cidadão com direitos constitucionais mantidos, o preso deve ter o cumprimento de sua sentença assumido como um processo de reabilitação, ou seja, um processo de preparação para o reingresso saudável à sociedade. Entende-se, então que "[...] a opção por tirar uma grande massa da população carcerária que está na ociosidade, colocando-a em salas de aula, não constitui privilégio - como querem alguns - mas, sim, como uma proposta que atenda aos interesses da própria sociedade (JULIÃO, 2012, p. 212). Todavia, dados de uma pesquisa inédita, realizada pelo Instituto de Pesquisa Econômica Aplicada (IPEA), a pedido do Conselho Nacional de Justiça (CNJ), intitulada Reincidência criminal no Brasil, revelaram que em 2015 havia uma taxa de $24,4 \%$ de reincidência, ou seja, a cada quatro ex-condenados, um volta a ser recluso por algum novo crime no prazo de cinco anos. Na comparação entre o percentual de reincidentes versus o nível de escolaridade, a pesquisa aponta:

De acordo com dados do Censo de 2010, o Brasil possui uma taxa de analfabetismo de $9,6 \%$ na população com 15 anos ou mais. Contudo, na amostra geral de apenados, os sem instrução ou com ensino fundamental perfazem $75,1 \%$ do total, proporção que é ainda mais contundente entre os reincidentes, nos quais $80,3 \%$ da amostra encontram-se nessa categoria. (IPEA, 2015, p. 26)

Depreende-se, do fragmento acima, que o percentual de presos com pouca ou nenhuma instrução supera 3/4 do total, confirmando que o baixo nível de escolarização pode ser um dos fatores que corroboram o alto índice de criminalidade no país. Outro aspecto a ser levado em consideração é a taxa de reincidentes, na qual constata-se que mais de $80 \%$ dos presos possui baixo nível de escolaridade. A respeito do processo de reabilitação da mulher em situação de prisão, Cunha (2010, p. 163) enfatiza que “[...] o processo de ressocialização deve abranger, necessariamente, os aspectos que envolvem a construção da imagem da mulher, concreta e subjetiva, o papel da educação, da qualificação e do trabalho no cárcere". Dessa forma, a ressocialização da reeducanda deve ser inerente às esferas social, familiar e política.

Segundo Silva (1997, p. 176) “[...] os efeitos mais duradouros do processo de institucionalização são os danos causados à constituição da identidade, a afirmação do 'estigma', a incorporação do sentimento de inferioridade e a redução significativa da autoestima". Consequências essas que, ao serem associadas ao sexismo, fortalecem assim o sentimento de inferioridade das mulheres perante os homens. Fato determinante que torna o processo de ressocialização da mulher, em situação de prisão, tão importante e, ao mesmo tempo, complexo, para alunas e professoras que atuam no ambiente prisional. Nesse sentido, a educação ofertada a essas alunas deve ser diferenciada da praticada nas escolas extramuros, visto que elas buscam, por 
meio da escolarização, não apenas a elevação da escolaridade, mas também a reinserção saudável à sociedade.

Diante do panorama configurado pelo processo de ressocialização, o INFOPEN (2016) aponta que apenas $12 \%$ da população carcerária do Tocantins tem acesso à educação. Entre os presídios que promovem a assistência educacional no estado está a UPF de Pedro Afonso que busca a ressocialização das detentas por meio do estudo. No que diz respeito aos benefícios da reabilitação, Julião (2016, p. 74) argumenta que:

[...] a educação pode preponderantemente assumir papel de destaque, pois, além dos benefícios da instrução escolar e de formação social, o preso pode vir a participar de um processo de modificação de sua visão de mundo, contribuindo para a formação do senso crítico, melhorando o seu comportamento na vida carcerária.

Assim sendo, é de fundamental importância compreender as especificidades do perfil do docente que trabalha no ambiente prisional, bem como os desafios da ressocialização do aluno / preso. A esse respeito, Paiva (2007, p. 46) nos esclarece que "A prática pedagógica em condições adversas e ameaçadoras pode significar um desafio para muitos, impelidos a compreender as razões do cárcere e contribuir com processos de aprendizado para sujeitos privados da liberdade e do saber sistematizado".

Nessa perspectiva, são necessários estudos que focalizem os desafios que o processo de ressocialização impõe à prática docente, objetivando-se analisar a natureza das contribuições advindas da formação dos educadores. Isso posto, essa pesquisa se propôs a investigar aspectos da prática pedagógica dos professores que atuam na educação prisional ofertada na UPF de Pedro Afonso, relacionando-os às necessidades e demandas socioeducativas das reeducandas inseridas na EJA.

\section{PROCEDIMENTOS METODOLÓGICOS}

A estratégia de pesquisa utilizada foi o estudo de caso e o grupo escolhido para a aplicação da pesquisa foi composto por professoras e alunas da UPF feminina de Pedro Afonso. Os depoimentos das entrevistadas foram colhidos pelo método proposto pela história oral, que é entendida por Thompson (2002, p. 9) como “[...] a interpretação da história e das mutáveis sociedades e culturas através da escuta das pessoas e do registro de suas lembranças e experiência". Por essa ótica, apreendemos, mais especificamente, a história oral temática, modalidade que é definida por Alberti (2005, p. 38):

Em geral, a escolha de entrevistas temáticas é adequada para o caso de temas que têm estatuto relativamente definido na trajetória de vida dos depoentes, como, por exemplo, um período determinado cronologicamente, uma função desempenhada ou o envolvimento e a experiência em acontecimentos ou conjunturas específicas. Nesses casos, o tema pode ser de alguma forma "extraído" da trajetória de vida mais ampla e tornar-se centro e objeto das entrevistas. Escolhem-se pessoas que dele participaram ou que dele tiveram conhecimento para entrevistá-las a respeito.

Ainda segundo a mesma autora, "As entrevistas temáticas são aquelas que versam prioritariamente sobre a participação do entrevistado no tema escolhido" (ALBERTI, 2005, p. 37). Desse modo, essa pesquisa focou nas narrativas da vida escolar, tanto fora como dentro da 
prisão, de alunas e suas professoras ouvidas por meio da história oral temática. Pela análise das memórias recuperadas e acolhidas por essas mulheres, procuramos compreender como se dá, na EJA, a busca pela efetiva ressocialização das presas.

A pesquisa teve como objetivos conhecer como é realizada a seleção das professoras que atuam no cárcere; investigar quais e como são desenvolvidas, no ambiente prisional, concepções e práticas pedagógicas dessas educadoras; bem como investigar contribuições à educação ofertada para a ressocialização das internas que optaram por voltar a estudar na prisão.

O local escolhido para a realização dessa investigação foi o ambiente escolar, que funciona dentro da UPF de Pedro Afonso, como extensão do Colégio Estadual Ana Amorim que, desde 2014 dispõe de parceria com a Secretaria de Estado de Defesa Social. As aulas acontecem dentro da unidade prisional, em uma sala adaptada com carteiras, armários, arcondicionado e quadro branco. O período de aulas é de segunda a sexta-feira, aulas desenvolvidas no sistema multisseriado em três divisões: o ensino fundamental I e o ensino fundamental II (do $1^{\mathrm{a}}$ ao $9^{\mathrm{a}}$ ano), são ofertados no período matutino; o ensino médio no período vespertino, sendo que cada série corresponde a seis meses de aula.

As entrevistadas que constituíram o corpus da pesquisa foram escolhidas por meio do seguinte critério: terem sido professoras da escola; serem alunas da escola que funciona dentro da UPF. Entre as reeducandas foram selecionadas somente as que, além de estudarem na unidade, apresentassem boa saúde e discernimento para compreender todo o processo de desenvolvimento da pesquisa. No que se refere às professoras, o critério de seleção foi o mesmo utilizado para as alunas, excluídos os professores afastados da escola, independentemente do motivo.

$\mathrm{Na}$ unidade prisional, locus da pesquisa, não há um local reservado para o planejamento das educadoras. Diante disso, a sala de recursos audiovisuais do Colégio Estadual Ana Amorim foi o ambiente escolhido para a realização das entrevistas com as professoras. Perante a situação de prisão em que se encontravam as demais participantes, o espaço escolhido para a coleta das entrevistas individuais foi a sala de atendimento médico, por ser privada e silenciosa.

No intuito de otimizar o tempo disponível, e impedir a perda de informações, o registro das entrevistas foi realizado em um gravador digital, conforme orientações da história oral. A ferramenta utilizada foi de grande valia, pois “[...] é o gravador que permite falar de produção de documentos, no retorno à fonte, na montagem de acervos de depoimentos, na autenticidade de trechos transcritos e na análise de entrevistas". (ALBERTI, 2005, p. 203)

As entrevistas realizadas individualmente foram transcritas na íntegra e acompanhadas de todas as informações das participantes, bem como do local e duração das entrevistas, data e horário de início e término. As participantes que aceitaram narrar suas experiências educacionais foram três internas: Santos, de 43 anos, solteira, e estudando no $2^{\circ}$ ano do ensino fundamental; Sousa, de 30 anos, solteira, cursando o $2^{\circ}$ ano do ensino médio; e Melo, de 23 anos, solteira, cursando o $1^{\circ}$ ano do ensino médio. Também foram entrevistadas quatro professoras: Moraes, licenciada em pedagogia, 47 anos, solteira, trabalhando na EJA desde 2014, e acumulando 28 horas semanais em sala de aula; Medeiros, licenciada em pedagogia, 38 anos, casada, trabalhando na EJA desde 2014 e lecionando 29 horas semanais; Araújo, licenciada em matemática, 26 anos, solteira, trabalhando na EJA desde 2017 e totalizando uma carga horária de 35 horas semanais; e Santos, licenciada em pedagogia, 45 anos, casada, trabalhando na EJA desde 2015 e totalizando uma carga horária de 30 horas semanais.

Em seus depoimentos, as professoras e as alunas se dispuseram a dar seus testemunhos acerca das memórias guardadas e opiniões mediante a assinatura de um Termo de Consentimento 
Livre e Esclarecido (TCLE), o qual apresenta informações acerca da pesquisa, de seus objetivos e do direito de desistir de participar a qualquer tempo. Documento que, depois de lido e elucidado, foi assinado tanto pelas participantes como pela pesquisadora, sendo que cada uma das partes permaneceu com uma via original de tal documento.

\section{POR DETRÁS DAS GRADES: NARRATIVAS DE PROFESSORAS E ALUNAS}

No intuito de compreendermos como se desenvolve o processo de ensino e aprendizagem e os desafios inerentes à prática docente na UPF de Pedro Afonso, expomos, nesta seção, parte dos resultados provenientes da investigação científica realizada em nível de mestrado. A partir do extenso material narrativo coletado, muitos foram os aspectos passíveis de serem analisados, no entanto, buscou-se interpretar os que respondem ao objetivo proposto nesse recorte da pesquisa, que é conhecer os desafios a que estão expostas, diariamente, professoras que atuam na UPF de Pedro Afonso.

Ao analisar as narrativas, optou-se por trazer à tona as falas transcritas na íntegra, tal qual foram relatadas pelas alunas e professoras. Foram analisados e categorizados os elementos presentes nas declarações das discentes e que respondem às indagações feitas anteriormente. Para tanto, questionamos, inicialmente a elas, o que as motivou a voltarem a estudar na escola do presídio. A aluna Santos (2019), a esse respeito, relatou:

Incentivou foi as meninas também, aqui é muito bom, tô gostando dos estudos, as professoras e a direção são tudo muito bom, pessoal bom, a diretora. Eu não tenho que dizer dessa unidade prisional, né? Não pra mim ficar, porque quero ter minha liberdade. Mas eu tô desenvolvendo, tô lendo mais, tô dando conta já de escrever, já. As professora são muito boa, ensina a gente bem, tem paciência.

Por meio das narrativas, percebemos que um dos principais fatores que fizeram com que as alunas buscassem retornar às aulas foi, de fato, a atuação das professoras envolvidas nesse processo. Nessa perspectiva, a aluna Melo (2019) narrou o motivo que a fez retomar os estudos na prisão:

Assim, porque, eu parei de estudar, mas quando eu tive meus menino, que eu
parei um pouco pra pensar... minha mãe sempre me dava conselhos, minha mãe
sempre dizia: E... volta a estudar, vai estudar, fazer curso, pra você arrumar um
emprego e tudo. Aí quando eu cheguei aqui dentro, eu vi as menina interessada,
tudo querendo ir pra escola, aí quando eu cheguei, tem uma menina que me
apoiou muito, me ajudou muito, me ensinou muita coisa aí dentro, agradeço
ela. A I... falou assim, vai estudar, é bom pra ti que tu estuda, que as professoras
são ótimas professoras, e a escola é boa, tu estuda, todo mundo é unido, até te
ajuda, a remir até sua pena, elas falaram. Não, então tá bom, vou pedir pra
colocar meu nome, aí botaram, e eu comecei a gostar.

Outro fato, igualmente importante, é conhecer a origem da presença das professoras na UPF de Pedro Afonso. Buscou-se, então, conhecer se o fato de trabalharem na prisão decorreu de opção pessoal ou de imposição. Registramos, nessa perspectiva, o que é pontuado por Araújo e Leite (2013). Segundo as autoras, grande número de professores que se encontram em atuação nos sistemas penitenciários não fez essa escolha. Em que pese, entretanto, a natureza dessa inserção, Duarte (2013, p. 30), no artigo "Celas de aula": o exercício da professoralidade nos presídios, argumenta que "[...] diante de um perfil que exige tantas qualidades, torna-se um ato de 
negligência, tanto para os alunos como para os professores despreparados, delegar uma sala de aula para um docente sem as reais condições para o trabalho".

No entanto, constatamos que foram as educadoras entrevistadas que optaram por atuar na educação prisional, visto que aceitaram um convite da Diretoria Regional de Ensino da cidade de Pedro Afonso. Portanto, são profissionais contratadas exclusivamente para esse fim, conforme esclarece a professora Medeiros (2019).

Bom, é feito assim, uma entrevista né? Com o profissional e eles procuram sempre uma pessoa que seja paciente, que seja reflexivo, né? E que saiba respeitar um cidadão. Não é porque as meninas estão lá, né? Elas estão pagando por um crime. Então não cabe a mim julgá-las. Então nós temos que ter... Foi feito essa entrevista baseada nesses critérios.

A esse respeito, é inegável que a atuação motivadora e transformadora do professor se mostre fundamental no processo de reeducação da pessoa em situação carcerária. Portanto, é importante que se compreenda qual é o efetivo papel do docente diante do processo de ressocialização do preso, e se esse profissional é de fato preparado, durante sua formação, para enfrentar esse tipo de desafio. Nessa concepção, quando foi indagado às professoras se tiveram capacitação específica para atuar na educação na prisão, a resposta foi um sonoro "não", como é enfatizado por Moraes (2019): “Antes não, né. E durante recebemos apenas uma. Uma, né? Que essa foi voltada para o conhecimento do sistema prisional no Tocantins. Entendeu? Apenas isso". Relato esse corroborado por Araújo (2019):

Não. Eu não tive nenhuma formação, porque no momento que teve a formação com as meninas eu não estava trabalhando ainda. Eu comecei esse ano. Mas eu contei com a ajuda de minhas colegas, né? Como que trabalha, o que deve ser feito, as coisas que devo ou não levar pra sala de aula, por exemplo.

Com relação às práticas pedagógicas, necessário se faz debater não somente como lidar com a aluna reclusa, mas também a necessidade de incluirmos currículos adequados por meio de conteúdos e práticas voltados à educação no cárcere, e que considere a bagagem de concepções político-sociais que faz diferença entre essas alunas e as demais do ensino regular. Ressaltando que os conteúdos teórico-conceituais de seus currículos devem ser considerados e aplicados de forma diferenciada dos demais.

Sobre o fato de a formação docente abordar ou não o tema educação e prisão, Moraes (2019) foi categórica: "Não, na graduação não. Porque na graduação ela é voltada para o ensino regular e a educação prisional é nova assim, então a gente tá aí na batalha. Entendeu? Nas novas descobertas...” o que é complementado por Medeiros (2019):

Não, preparada durante a minha graduação não, né? Porque prepara-se para o trabalho no ensino regular, né? $\mathrm{E}$ a educação em prisões no Tocantins, especificamente na nossa cidade, é nova. Então nós não temos, não fui preparada na minha graduação.

É possível depreender, consonante às narrativas, que não são exigidas e nem ofertadas condições prévias de conhecimento para o professor trabalhar com jovens e adultas privadas de liberdade na unidade prisional pesquisada. Mas, das quatro professoras entrevistadas, três afirmaram que antes de trabalharem na educação na prisão atuaram na educação diferenciada, 
fosse ela indígena, ProJovem ${ }^{1}$ ou EJA, fator que, segundo elas, contribuiu para efetivar a contratação, conforme narrativas a seguir:

Eu não escolhi. Eu fui convidada a trabalhar na educação prisional. Pra mim foi uma oportunidade muito boa, porque é uma coisa nova pra nós, porque no nosso curso nós não estudamos a educação nas prisões. Aí recebi aquele convite da diretora da escola. Mas antes de trabalhar na prisional, eu já trabalhava na EJA. Dava aula para jovens e adultos da EJA. (SANTOS, 2019)

Bom, eu sempre trabalhei em educação diferenciada. Trabalhei na indígena, trabalhei nos programas de recuperação, ProJovem Campo, ProJovem Urbano, então eu fui convidada. O pessoal tinha o meu currículo e quando surgiu as turmas aqui na Unidade Feminina de Pedro Afonso, eles me ligaram e me fizeram o convite, eu aceitei. (MEDEIROS, 2019)

No intuito de conhecer quais e como são desenvolvidas, no ambiente prisional, as concepções e práticas pedagógicas dessas educadoras, indagamos às próprias alunas o que elas achavam das professoras e das metodologias aplicadas em sala de aula. Souza (2019), a esse respeito, narrou:

São ótimas. Pra mim elas são como se fossem minha segunda mãe, minhas irmãs que eu não tenho aqui, porque com elas a gente chega aqui, a gente conta o que tá passando, a gente desabafa, aí elas escutam, elas dão conselhos pra nós, segunda amiga.

Nesse sentido, aos conhecimentos escolares são agregados valores fundamentais para a formação humana e para a construção de uma consciência crítica diante de questões sociais, amparadas pelo empoderamento que todos os dias é incentivado pelas professoras atuantes no espaço prisional.

Buscou-se, então, satisfazer a inquietação quanto à necessidade, ou não, de metodologias e / ou práticas diferenciadas no trabalho com alunas em situação de prisão. Dessa forma, procurou-se dialogar com as narrativas de Santos (2019) e Araújo (2019), sobre suas respectivas práticas pedagógicas.

Sim, lá nós usamos muito, assim, o material xerocopiado, livros pra pesquisa, elas não têm acesso a nenhum aparelho tecnológico, sabe? Então a gente usa muito assim de levar livros, material assim mesmo bem amplo pra elas entenderem, ter mais facilidade pra elas pra aprenderem, então a gente trabalha muito esse material diferenciado com elas.

Olha, eu uso material impresso, livros pra pesquisa, já que elas não têm acesso nenhum, de nenhuma maneira à internet, né? Então, livros pra pesquisa. Nem computadores, nada. Então procuro trazer o material o mais resumido, pra eu aproveitar o máximo de tempo, né? E algumas dinâmicas pra animar um pouco o ambiente, né? E, às vezes, assim, dependendo como elas estão, do emocional delas, a gente procura trabalhar uma aula mais... mais light, sem exigir tanto, mas de toda forma sempre buscando dar o conteúdo. Não é permitido levar, por exemplo, levar alguns materiais cortantes, estilete, por exemplo, que a gente, o professor costuma usar na escola. Tesoura pontiaguda, quando você for trabalhar com esse tipo de material, você tem que passar pela Direção pra dar

\footnotetext{
${ }^{1}$ É um programa federal desenvolvido no Tocantins pela Secretaria Estadual da Juventude (SEJUV) com o objetivo de promover a capacitação profissional do jovem e sua inclusão no mundo competitivo do trabalho.
} 
olhada no seu material pra ver o que pode ou não entrar; celular, chave de moto, essas coisas assim.

Fica evidente, nas narrativas acima, que as professoras utilizam com frequência tanto o livro didático quanto as atividades fotocopiadas devido à ausência de outros materiais pedagógicos que permitam a execução de métodos diferenciados dos existentes. Tais limitações se mostram como verdadeiros desafios ao exercício do professor em um ambiente tão estereotipado como as instituições prisionais. Além da carência de materiais didáticos, identificamos também, como dificultador da prática docente, a oferta simultânea de várias séries distintas em uma mesma sala de aula, conforme narrado por Santos (2019): "Por ser... o sistema lá multisseriado, a gente vê assim, muita, as dificuldades das alunas, muitas vezes, por elas nunca nem terem pisado os pés na sala de aula, o que acontece muito em nossa sala de aula mesmo" e Moraes (2019) "Por ser tratado como multisseriado é... onde tem várias é. Então é, e com alunos que estão privados de liberdade tem que tornar as aulas mais assim dinâmicas, diferenciadas, mais atrativas, por isso". O funcionamento do sistema educativo na prisão é assim esclarecido por Araújo (2019):

É o seguinte, é porque nós temos só uma sala de aula e, geralmente, a cada semestre, como é modalidade EJA, né? Às vezes nós temos quatro turmas, às vezes nós temos cinco ou seis, depende da escolaridade de cada uma. Então é... por ter só uma turma, geralmente ficam duas, três ou até quatro turmas em um período, então a dificuldade é muito grande em trabalhar com turmas multisseriadas. Por mais que sejam poucas alunas, mas eu tenho que dar atenção a todas. Então, esse trabalho dificulta um pouco. É bem difícil fazer esse trabalho em turmas multisseriadas.

De posse do conhecimento quanto às dificuldades e limitações impostas à tentativa de se ensinar numa "cela" de aula, instigamos as professoras a conceberem uma autorreflexão quanto à identidade, papel e desafios da sua profissão frente a um projeto tão difícil. Por fim, buscamos conhecer os desafios de exercer a docência no espaço prisional e que assim foram externados pela professora Moraes (2019): “O emocional. O emocional das reeducandas e a rotatividade" e por Santos (2019):

Além do emocional delas, que isso aí influencia muito, porque tem dia que elas chegam lá muito desanimadas, aí a gente tem que ser assim aquela amiga, mãe, psicóloga, sabe? E, também, a rotatividade lá que é muito grande que você pensa que tá com aquela aluna lá, aí você chega lá e já foi embora. Porque a rotatividade é muito grande. E isso atrapalha muito, muitas vezes a gente dá prosseguimento, assim, nas nossas aulas.

Da narrativa acima evidencia-se que "[...] não são raras as vezes em que ser professor na prisão é atuar em diversas frentes, às vezes, sendo necessário assumir papéis que não lhes competem, como 'mãe' e 'psicóloga', mas que são de extrema importância para concretizar o trabalho de autonomia e empoderamento que se busca" (CARVALHO, 2019). Ao demonstrarem sensibilidade em perceberem que o emocional das alunas importa, inclusive influenciando no rumo que a aula pode tomar no dia em questão, as professoras mostram que se solidarizam com o bem-estar psicológico delas, comportamento humanizado, que nem todos os profissionais da educação entre grades, detêm.

Por fim, questionamos ao grupo de professoras participantes se para elas a educação contribui para o processo de ressocialização das alunas. Sobre isso, Araújo (2019) pontua: 
Eu acho que sim. Porque, a educação em si, ela é transformadora, né? A educação, ela tem um papel de tornar, tornar a pessoa, o indivíduo em um cidadão íntegro, então, se elas não deram valor, se elas foram motivadas da maneira certa aqui fora, lá dentro, né? Com essa oportunidade que elas têm de ter um contato mais direto com os professores, né? E por ter nada que tire a atenção delas lá dentro, então a oportunidade delas realmente serem reeducadas é bem maior.

As alunas também enfatizaram a importância da educação para o processo de reabilitação, a exemplo, o fragmento da entrevista de Melo (2019): "Sim. Eu penso assim, eu estudando, terminando meus estudos, posso fazer curso, posso ter um emprego bom, apesar de eu tá aqui dentro, mas, errar é humano, então a gente pode mudar e procurar outra rotina, trabalho". A partir dos relatos, constatou-se que a atuação motivadora das docentes foi fundamental no processo de ressocialização de suas alunas. Fato é que a educação não dá conta de tudo, porém, ela é fundamental nesse processo (MEDEIROS, 2016), pois, como já afirmava Freire (2000, p. 67), em sua terceira carta pedagógica, "[...] sem ela, a sociedade não muda".

\section{REFLEXÕES SOBRE A EDUCAÇÃO NO CONTEXTO DA PRISÃO}

Ao se discutir ações pedagógicas que visam à ressocialização de pessoas em situação de prisão, por meio da elevação do nível de escolaridade, deve-se levar em consideração a necessidade de incluir, nos currículos das licenciaturas, conteúdos e práticas voltadas à educação no cárcere, segundo esclarecido pelas professoras entrevistadas. Assim, analisar e debater tanto o currículo dos cursos de formação de professores que trabalham no sistema penitenciário, quanto o currículo que é ofertado aos alunos reclusos, é de suma importância para o desenvolvimento de um trabalho mais eficiente e a oferta de uma educação que efetivamente ressocialize.

A respeito das professoras, conforme narrado por elas e por suas respectivas alunas, as mesmas conferem sentido e responsabilidade à função que exercem, e mesmo sem receber capacitação específica e com os poucos materiais que lhes são disponíveis buscam a consolidação de uma proposta pedagógica efetiva, o que demonstra o compromisso político-social firmado com a docência. A esse respeito, Onofre (2007, p. 12) salienta que:

Há que se pensar, portanto, em uma educação que seja capaz de incorporar, em seu processo pedagógico, o desenvolvimento de ações de conhecimento que levem o indivíduo a: primeiro, conhecer o mundo; segundo conhecer-se como sujeito capaz de agir nesse mundo e transformá-lo.

As análises nos permitem afirmar que as profissionais que atuam na UPF de Pedro Afonso preocupam-se em desenvolver práticas transformadoras, priorizando, em sala de aula, o ser humano e suas especificidades, ações que se tornaram incentivos para que as reeducandas retomassem os estudos, conforme narrado pelas próprias alunas.

Foi observado, também, que as professoras atuantes no presídio pesquisado, mesmo com material pedagógico limitado, buscam refletir sobre as práticas ali desenvolvidas, de forma geral, e sobre a própria atuação, de forma específica. Objetivando tornar a educação carcerária mais humanizada e consciente, não se pode ignorar a especificidade de uma educação que tem como cenário a busca pela reintegração social. Assim sendo, o trabalho desenvolvido por elas não está apenas ancorado na produção do conhecimento, mas também é perpassado pelo processo de reinvenção e empoderamento de suas alunas. 
A partir dos relatos, verificou-se que a atuação motivadora das docentes se mostrou fundamental na busca pela ressocialização de suas alunas, sendo que o trabalho de resgate social e a transformação de vida das mulheres no cárcere são os principais desafios a serem superados pelas professoras. Fato é que a educação não dá conta de tudo, porém, ela é fundamental nesse processo, pois não há como falar em projetos para o futuro sem falar em recomeço, e a educação, ao promover reflexão e debate, torna-se o caminho para a mudança.

Portanto, é possível compreender, a esse respeito, que a educação oferecida para as reeducandas é diferenciada da ofertada aos alunos regulares, visto que elas buscam, por meio da escolarização, não apenas a elevação da escolaridade e a remição da pena, mas também um futuro melhor fora da prisão, promovido pelo empoderamento alcançado. Somado a isso, temos os dados da pesquisa realizada pelo IPEA, que confirmam o aumento da escolaridade como um indicativo para a redução da reincidência entre os presos postos em liberdade.

\section{ALGUMAS CONSIDERAÇÕES}

São muitas as mazelas que assolam as cadeias brasileiras. Entre elas estão a superlotação, condições desumanas e um processo de ressocialização pouco eficiente. Essa é uma realidade que todos os dias bate à nossa porta. Assim, necessário se faz buscar caminhos que desmitifiquem os estigmas que acometem a população carcerária, que cresce assustadoramente nos presídios do país.

Mesmo sendo um dos principais meios de reintegração e readaptação de presos e presas, a educação entre grades é, muitas vezes, vista de maneira jocosa e desrespeitosa. Há que se considerar, entretanto, que a pessoa em situação de privação de liberdade está reclusa por um determinado período e que, nesse espaço de tempo, é dever do Estado atuar como ressocializador, com vista a devolvê-lo reabilitado à sociedade, pronto para uma convivência saudável. Infelizmente, o que se vê é o oposto. Muitas vezes, da cadeia são egressas pessoas piores do que quando entraram, pessoas marcadas por condições subumanas e pelo descaso do poder público, fato que pode ser superado com métodos efetivos de ressocialização.

Posto isso, é nesse momento que uma educação humanizada, ao tomar a linha de frente, pode transformar e ressocializar. Como é o caso da educação ofertada na UPF de Pedro Afonso, onde alunas e professoras se juntaram em prol de um bem maior, a busca pela ressocialização por meio do estudo, não só das reeducandas, mas também das famílias e de toda uma comunidade ligada, direta ou indiretamente, àquelas mulheres.

Por fim, infere-se, a partir das narrativas analisadas, que algumas das adversidades enfrentadas pelas educadoras advêm do fato de lidarem com diferentes fatores que interferem em suas práticas pedagógicas, tais como: o sistema multisseriado, materiais didáticos limitados e, principalmente, a baixa estima que acomete as reeducandas do presídio, ocasionada tanto pela reclusão a uma instituição prisional, como pelo afastamento de familiares e amigos. Dessa forma, é que muitas vezes é necessário que as professoras atuem em outras frentes, sempre tentando driblar as diversas dificuldades encontradas, no desígnio de que alunas e ressocialização se encontrem. 


\section{REFERÊNCIAS}

ALBERTI, Verena. Manual de história oral. Rio de Janeiro: Ed. FGV, 2005.

ALMEIDA, Sandra Maciel. Educação de mulheres e jovens privadas de liberdade: vulnerabilidade socioeducacional e contingências da privação. Jundiaí, São Paulo: Paco Editorial, 2016.

ANGOTTI, Bruna. Entre as leis da ciência, do Estado e de Deus - o surgimento dos presídios femininos no Brasil. 315f. Dissertação, Mestrado em Antropologia Social, Universidade de São Paulo - Faculdade de Filosofia, Letras e Ciências Humanas. São Paulo, 2011.

ARAÚJO, Stephane Silva; LEITE, Maria Cecília. A assistência educacional no sistema penitenciário federal. Revista Eletrônica de Educaşão, v. 7, n. 1, 2013.

BRASIL. Constituição da República Federativa do Brasil. Brasília, 1988.

BRASIL. Lei n. 12.245 de 24 de maio de 2010. Altera o Art. 83 da Lei no 7.210, de 11 de julho de 1984 - Lei de Execução Penal, para autorizar a instalação de salas de aulas nos presídios. Diário Oficial da República Federativa do Brasil. Brasília, Distrito Federal, 2010.

BRASIL. Lei n. 7.210, de 11 de julho de 1984. Institui a Lei de Execução Penal. Diário Oficial da República Federativa do Brasil. Brasília, Distrito Federal, 1984.

BRASIL. Lei n. 7.210, de 11 de julho de 1984. Institui a Lei de Execução Penal. Diário Oficial da União: seção 1, Brasilia, Distrito Federal, ano 139, n. 8, p. 1-74, 11 jan. 2002.

BRASIL. Lei de Execução Penal. Lei n. 7.210, de 11 de julho de 1984. Diário Oficial da República Federativa do Brasil. Brasília, Distrito Federal, 1984.

BRASIL. MINISTÉRIO DA JUSTIÇA. Departamento Penitenciário Nacional. Sistema Integrado de Informacõos Penitenciárias - InfoPen. Brasília, Distrito Federal, 2016.

BRASIL. MINISTÉRIO DA JUSTIÇA. Departamento Penitenciário Nacional (2016). Sistema integrado de informações penitenciárias - InfoPen. Disponível em: https://www.justica.gov.br/noticias/mj-divulgara-novo-relatorio-do-infopen-nesta-tercafeira/relatorio-depen-versao-web.pdf. Acesso em: 28 mar. 2020.

CARVALHO, Kely Rejane Souza Anjos. Luzes na escuridão: narrativas no cárcere. $159 f$. Dissertação, Mestrado em Educação. Programa de Pós-graduação em Educação. Universidade Federal do Tocantins, Palmas, 2019.

CUNHA, Elizângela Lelis. Ressocialização: O desafio da educação no sistema prisional feminino. Cad. Cedes. Campinas, v. 30, n. 81, p. 157-178, maio / ago. 2010.

DICIONÁRIO ONLINE DE PORTUGUÊS. Reeducando. In: Porto: 7Graus, 2019. Disponível em: https://www.dicio.com.br/reeducando/. Acesso em: 23 mar. 2020.

DUARTE, Alisson José Oliveira. Celas de aula: o desafio da professoralidade no presídio. Revista Encontro de Pesquisa em Educação, v. 1, n. 1, p. 25-36, 2013.

FOUCAULT, Michel. Vigiar e punir: nascimento da prisão. Rio de Janeiro: Vozes, 1987.

FREIRE, Paulo. Pedagogia da indignação: cartas pedagógicas e outros escritos. Apresentação de Ana Maria Araújo Freire. Carta-prefácio de Balduino A. Andreola. São Paulo: Ed. UNESP, 2000.

INSTITUTO DE PESQUISA ECONÔMICA APLICADA. Reincidência Criminal - Relatório de Pesquisa. Rio de Janeiro, 2015.2 Disponível em: http://www.ipea.gov.br/agencia/images/stories/PDFs/relatoriopesquisa/150611_relatorio_rein cidencia criminal.pdf. Acesso em: 28 mar. 2020. 
JULIÃO, Elionaldo Fernandes. A ressocialização através do estudo e do trabalho no sistema penitenciário brasileiro. 450f. Tese. Doutorado em Ciências Sociais. Centro de Ciências Sociais. Instituto de Filosofia e Ciências Humanas. Rio de Janeiro, 2009.

JULIÃO, Elionaldo Fernandes. Educação e trabalho como programas de "reinserção social". In: LOURENÇO, Arlindo Silva; ONOFRE, Elenice Maria Camarosano (orgs.). Espaço da prisão e suas práticas educativas: enfoques e perspectivas contemporâneas. São Carlos: EdUFSCar, 2012. p. 191222.

ONOFRE, Elenice Maria Cammarosano. Escola da prisão: espaço de construção da identidade do homem aprisionado? In: ONOFRE, Elenice Maria Camarosano (org.). Educação escolar entre as grades. São Carlos: EdUFSCar, 2007. p. 29-50.

PAIVA, Jane. Conteúdos e metodologia: a prática docente no cárcere. Boletim Informativo do Programa Políticas da Cor. n. 14. Rio de Janeiro: Laboratório de Políticas Públicas da UERJ, 2007.

SILVA, Roberto. Os filhos do governo. São Paulo: Ática, 1997.

THOMPSON, Paul. A voz do passado: história oral. Rio de Janeiro: Paz e Terra, 2002.

\section{RELAÇÃO DAS ENTREVISTADAS DO ESTUDO}

Alunas:

MELO. Entrevista concedida à K.R.S.A.C. Em Pedro Afonso - TO, 2019.

SANTOS. Entrevista concedida à K.R.S.A.C. Em Pedro Afonso - TO, 2019.

SOUSA. Entrevista concedida à K.R.S.A.C. Em Pedro Afonso - TO, 2019.

Professoras:

ARAÚJO. Entrevista concedida à K.R.S.A.C. Em Pedro Afonso - TO, 2019.

MEDEIROS. Entrevista concedida à K.R.S.A.C. Em Pedro Afonso - TO, 2019.

MORAES. Entrevista concedida à K.R.S.A.C. Em Pedro Afonso - TO, 2019

SANTOS. Entrevista concedida à K.R.S.A.C. Em Pedro Afonso - TO, 2019.

Submetido em marco de 2020.

Aprovado em abril de 2020.

\section{Informações das autoras}

Kely Rejane Souza dos Anjos de Carvalho

Mestre em Educação pelo Programa de Pós-Graduação em Educação (PPGE) pela Universidade Federal do Tocantins. Pedagoga - orientadora educacional na Reitoria do IFTO.

E-mail: kelyrejanecarvalho@gmail.com

ORCID: https://orcid.org/0000-0001-6683-839X

Link Lattes: http://lattes.cnpq.br/5678865861173429 
Jocyleia Santana dos Santos

Doutora em História pela Universidade Federal de Pernambuco. Coordenadora do Programa de PósGraduação em Educação (PPGE) da UFT/CAPES. Coordenadora local do Doutorado em Educação PGDEA/Educanorte. Coord. Local do PROCAD AMAZONIA/UFT/CAPES/UFRN.

E-mail: jocyleiasantana@gmail.com

ORCID: http://orcid.org/0000-0003-2335-121X

Link Lattes: http://lattes.cnpq.br/8198025782417839

Daniela Patrícia Ado Maldonado

Doutora em Educação pela Universidade Estadual Paulista Júlio de Mesquita Filho (UNESP). Professora e Coordenadora do Núcleo de Orientação Psicológica e Educacional (NOPE), na União Educacional Superior do Médio Tocantins (UNEST), de Paraíso de Tocantins.

E-mail:ado_daniela@yahoo.com.br

ORCID: https://orcid.org/0000-0002-3728-3206

Link Lattes: http://lattes.cnpq.br/7529723315100324 